\title{
BIODIVERSIDADE NO CONTEXTO ESCOLAR: CONCEPÇÕES E PRÁTICAS EM UMA PERSPECTIVA DE EDUCAÇÃO AMBIENTAL CRÍTICA
}

\author{
Camila Martins ${ }^{1}$ \\ Haydée Torres de Oliveira ${ }^{2}$
}

Resumo: $O$ objetivo deste trabalho foi contribuir para a compreensão das concepções de estudantes e professoras do Ensino Fundamental II de uma escola municipal de São Carlos (SP) sobre o termo biodiversidade como subsídio para o desenvolvimento de ações educativas sobre a temática, por meio da elaboração participativa de um material didático em uma perspectiva de educação ambiental crítica. A pesquisa caracterizou-se pela abordagem qualitativa, sendo realizadas entrevistas e questionários com o público participante. As análises dos dados contribuíram para a elaboração participativa de uma proposta educativa intitulada Caixa da Biodiversidade, apresentando atividades com uma abordagem crítica sobre os contextos que envolvem a biodiversidade.

Palavras-chave: Concepções sobre Biodiversidade; Caixa da Biodiversidade; Educação Ambiental Escolar.

\footnotetext{
${ }^{1}$ Universidade Federal de São Carlos, Departamento de Ciências Ambientais, Laboratório de Educação Ambiental. E-mail:ca_martins16@yahoo.com.br

${ }^{2}$ Universidade Federal de São Carlos, Departamento de Ciências Ambientais, Laboratório de Educação Ambiental. E-mail: haydee.ufscar@gmail.com
} 


\section{Introdução}

\section{A educação ambiental crítica e a conservação da biodiversidade}

Nas últimas décadas, a perda de habitats naturais, o desenvolvimento desenfreado de práticas degradantes e inadequadas sobre o meio ambiente, a expansão urbana, o crescimento demográfico, a industrialização e os hábitos de consumo inadequados vêm contribuindo para a crise e o desequilíbrio socioambiental da contemporaneidade. Neste contexto, a educação ambiental se apresenta como um campo que contribui para a transformação de atitudes e de decisões acerca dos problemas ambientais, sociais e políticos. Essa descrição é defendida por diversas/os autoras/es, sendo denominada de Educação Ambiental Crítica (EA Crítica), que segundo Carvalho (2004, p.18), é "o encontro da educação ambiental com o pensamento crítico dentro do campo educativo", em busca de uma compreensão das relações estabelecidas entre o ser humano e a natureza, além de "contribuir para uma mudança de valores e atitudes, culminando para a formação do sujeito ecológico". Guimarães (2004, p. 22) também sinaliza que o significado da EA crítica difere das demais categorizações existentes, uma vez que diz respeito a ações educativas que tem como objetivo "contribuir para a transformação de uma realidade que, historicamente, se coloca em uma grave crise socioambiental" e articular processos educativos que visem à modificação dos indivíduos de forma emancipada (LOUREIRO, 2004).

Diante do exposto, a educação ambiental se constitui como uma perspectiva para a superação dos problemas ambientais e sociais que norteiam a sociedade contemporânea, como as ameaças à biodiversidade.

Segundo Wals et al. (1999), diversas estratégias podem ser adotadas para que a conservação da biodiversidade seja considerada um elemento prioritário para a integridade e qualidade ambiental, como os instrumentos políticos, a educação, a pesquisa e a comunicação. Nesse sentido, a construção de políticas públicas e práticas educativas em ambientes formais e não-formais são ferramentas indispensáveis para a construção de novos valores e transformação da realidade socioambiental contemporânea, como as ameaças e conflitos existentes na conservação da biodiversidade.

\section{Conceitos atribuídos à biodiversidade}

Segundo a literatura, o termo biodiversidade - contração de diversidade biológica -, foi utilizado pela primeira vez por Walter G. Rosen e Edward O. Wilson, durante o National Forum on BioDiversity, realizado em Washington, em 1986 (OLIVEIRA; KAWASAKI, 2005). Para Wilson (1992, p.412), a biodiversidade é entendida como:

A variedade de organismos considerada em todos os níveis, desde variações genéticas pertencentes à mesma espécie até as diversas séries de espécies, gêneros, famílias e outros 
níveis taxonômicos superiores. Inclui variedade de ecossistemas, que abrange tanto comunidades de organismos em um ou mais habitats quanto às condições físicas sob quais elas vivem.

Considerando o conceito ecológico de biodiversidade, o Brasil é considerado o país com maior diversidade de vida existente, contando com sete biomas, dentre eles Amazônia, Mata Atlântica, Pantanal e Cerrado, que apresentam formas peculiares de fauna e flora contribuindo para a riqueza de espécies do país (RICKLEFS, 2003). Todavia, a biodiversidade torna-se cada vez mais ameaçada devida a uma série de causas naturais e artificiais. Dentre as causas naturais estão os processos de desertificação, as glaciações, as alterações na atmosfera e as atividades vulcânicas (BRASIL, 1998), que ocorreram durante diversas eras geológicas e contribuíram para a alteração da biota no planeta Terra. De acordo com Helene e Marcondes (1996) "ao mesmo tempo em que novas espécies vão surgindo em resposta às modificações do ambiente, outras já existentes vão desaparecendo por inadequação a essas modificações".

Em relação às causas artificiais da perda da biodiversidade, podem ser citados os processos antrópicos que vêm intensificando a crise ambiental e colocando em risco a sobrevivência dos elementos que compõem os cenários naturais, como animais e plantas, além de acelerar o desequilíbrio dos ecossistemas mundiais (ROOS, 2012). Como exemplo dessas ações antrópicas, está a destruição de habitats naturais; introdução de espécies exóticas e invasoras; exploração excessiva de espécies animais e vegetais; caça e pesca sem critérios; tráfico de fauna e flora silvestre; poluição das águas e atmosfera; ampliação desordenada das fronteiras agropecuárias; crescimento da população humana; industrialização; urbanização e mudanças climáticas.

O conhecimento e a percepção sobre a biodiversidade e a compreensão da necessidade de esforços para sua conservação vêm ganhando mais força e destaque em função do contexto socioambiental observado atualmente e, diante dessa situação, tornou-se indispensável a discussão de políticas públicas necessárias para a realização de medidas rápidas e efetivas para a conservação da biodiversidade.

Nesse contexto, durante a Conferência Rio - 92, foi assinado um acordo entre os países membros intitulado Convenção sobre Diversidade Biológica, a qual apresentava diretrizes, objetivos e ações que os países membros deveriam inserir em suas agendas governamentais para "gerir melhor os meios e os recursos naturais, numa perspectiva de desenvolvimento durável" (LÉVÊQUE, 1999). Essas diretrizes ampliam o termo biodiversidade, dando-Ihe sentidos para além do biológico, extrapolando para outros contextos e agregando valores como políticos, econômicos, sociais e culturais. O mesmo autor aponta que para muitos pesquisadores a biodiversidade é vista em diversas interpretações variando de acordo com a área de interesse de cada 
grupo, entretanto, os enfoques dados à ela não são independentes e perseguem um mesmo objetivo que é a conservação dos ambientes naturais com a participação do ser humano. Sendo assim, a biodiversidade torna-se um "conceito federativo", o qual faz correlação entre os conceitos ecológicos e sociais com o objetivo de realizar a gestão do ambiente e atentar para as questões econômicas que norteiam as suas estratégias de conservação.

Dentro dos diversos conceitos atribuídos, a Convenção sobre Diversidade Biológica (BRASIL, 1992, p.9) apresenta o seguinte:

A variabilidade de organismos vivos de todas as origens, compreendendo, dentre outros, os ecossistemas terrestres, marinhos e outros ecossistemas aquáticos e os complexos ecológicos de que fazem parte; compreendendo ainda a diversidade dentro de espécies, entre espécies e de ecossistemas. expressar:

Lévêque (1999) apresenta três níveis que a biodiversidade pode se

1) Diversidade de espécies: referente a identificação de espécies e formas que ocorrem em um determinado ambiente, ou seja, o número de espécies (riqueza);

2) Diversidade genética: afirma que as espécies apresentam constituição genética diferente umas das outras, correspondendo a variabilidade de genes e genótipos envolvidos na espécie;

3) Diversidade ecológica: que envolvem os ecossistemas que são compostos pelas espécies em questão e pelos elementos físicos, podendo distinguir numerosos ambientes como florestas, desertos, tundras, ambientes polares, entre outros.

Para Begon, Townsend e Harper (2005), o termo biodiversidade tem muitos significados na comunidade científica e no senso comum, e a ideia simplista de que é sinônimo de riqueza de espécies (ou seja, número de espécies em um determinado ambiente) ainda é muito difundida entre a comunidade científica, apesar das diretrizes da Convenção sobre Diversidade Biológica (BRASIL, 1992), mencionadas anteriormente. Entretanto, para os autores, a biodiversidade pode ser entendida em escalas acima e abaixo do nível de espécie, como a diversidade genética existente nas populações e a variabilidade de ambientes que essas espécies estarão dispersas.

Nesse sentido, observamos que tal conceito não é fixo e único (WALS, 1999), ou seja, ele é um termo polissêmico que apresenta diversos sentidos em diferentes contextos, desde o científico até o senso comum. Essa constatação tem implicações para o campo educativo, constituindo um desafio para 
educadoras e educadores ambientais conhecer os diversos níveis e sentidos referentes ao termo para poder explicitá-lo de forma adequada e correlacionálo com os valores econômicos, sociais, culturais e políticos. Nesse contexto, Thiemann (2013) analisou os sentidos atribuídos à biodiversidade por pesquisadoras/es e estudantes do Curso de Ciências Biológicas, procurando possibilidades e potencialidades em abordar a temática em uma perspectiva de EA crítica e, como resultado, observou uma diversidade de sentidos atribuídos ao termo, dentre eles as seguintes categorias: concretude, simbólico, conhecimento, holismo, caleidoscópio, oculta, ameaçada e inclusiva, evidenciado a caráter polissêmico da palavra biodiversidade.

\section{Interface entre biodiversidade e educação ambiental no contexto escolar}

Segundo um dos princípios da educação ambiental, pautados no Tratado de Educação Ambiental para Sociedades Sustentáveis e Responsabilidade Global (RIO DE JANEIRO, 1992), a educação é um direito de todas as comunidades e de todos os indivíduos, sem distinções culturais, sociais, étnicas, físicas, de gênero, idade e religião. A Política Nacional de Educação Ambiental destaca em seu artigo $2^{\circ}$, que a EA é vista como "um componente essencial e permanente na educação nacional, devendo estar presente, de forma articulada, em todos os níveis e modalidades do processo educativo, em caráter formal e não-formal' (BRASIL, 1999). Esses dois documentos oficiais trazem argumentos sobre os direitos que a população possui em relação aos princípios da educação ambiental no ambiente escolar, como uma estratégia para dialogar, refletir, contextualizar a difundir atitudes, valores e respeito em relação ao contexto socioambiental contemporâneo.

Nesse sentido, dados publicados pelo INEP (Instituto Nacional de Pesquisas Educacionais Anísio Teixeira), indicam que no ano de 2001 existiam cerca de 25,3 milhões de crianças com acesso à educação ambiental por meio da realização de atividades ou projetos de diferentes temáticas. No ano de 2004, esse quadro modificou-se para 32,3 milhões de crianças envolvidas em ações educativas. Ou seja, a demanda por atividades que envolvam os princípios da educação ambiental é presente nas instituições escolares em todos os níveis e modalidades. Dessa forma, aumenta a responsabilidade do Órgão Gestor - especificamente do MEC - em apoiar a comunidade escolar e formar educadoras/es que busquem conhecimentos, pesquisas e intervenções para trabalhar nesses ambientes de forma crítica (LOUREIRO; COSSÍO 2007).

Diversos trabalhos vêm sendo desenvolvidos sobre concepções de biodiversidade e práticas educativas no contexto escolar (GONZALESGAUDIANO, 2002; KAWASAKI; OLIVEIRA, 2003; OLIVEIRA; KAWASAKI, 2005; WEELIE, 2010; SILVA; SILVA, 2011; OLIVEIRA, MARANDINO, 2011). Castro (2009) realizou uma proposta de mapeamento ambiental na construção do termo biodiversidade e Cerrado com estudantes do ensino médio por meio de visita aos arredores da escola, permitindo que os participantes da pesquisa pudessem construir o conceito de biodiversidade de forma contextualizada e a 
partir da sua vivência e ações do cotidiano, contribuindo para a formação de conhecimentos mais concretos em relação à conservação da biodiversidade e do bioma Cerrado. Thiemann (2013), em sua pesquisa sobre sentidos atribuídos à biodiversidade, destacou seis sugestões de temas que poderiam contribuir para o processo de ensino-aprendizagem, sendo eles: experimentar a biodiversidade; exercitar diálogos/debates; perceber a importância da biodiversidade e os limites da interferência humana; biodiversidade no próprio território; superação da fragmentação do ensino. Essas sugestões indicam potencialidades para abordar o tema no contexto escolar de forma transversal aos demais conteúdos curriculares do ensino de ciências e biologia, como está destacado nos Parâmetros Curriculares Nacionais (BRASIL, 1997).

Bizerril e Faria (2003) investigaram o enfoque que é dado ao tema Cerrado no ensino fundamental do Distrito Federal, observando que geralmente é abordado nas disciplinas de Ciências e Geografia, destacando um reduzido conhecimento sobre a diversidade biológica do bioma e as ações impactantes, corroborando com a necessidade da implementação de práticas educativas em uma perspectiva de EA crítica e transformadora que problematize as questões que norteiam a conservação da biodiversidade próximas ao contexto local e regional dos estudantes. Nesse sentido de valorizar a realidade das pessoas envolvidas na pesquisa, Valenti (2014) problematizou a temática relacionada à conservação da onça parda (Puma concolor) no entorno de áreas protegidas a partir da visão dos participantes para identificar dimensões transformadoras para desenvolver ações de EA sobre a temática.

Após a revisão da literatura sobre com a importância de inserir no contexto escolar as temáticas relacionadas à conservação da biodiversidade em uma perspectiva de educação ambiental, podemos observar uma importante interface sobre a necessidade do estímulo aos programas, projetos ou ações na educação formal. Nesses espaços, cabe às escolas e às universidades, com a articulação de professoras/es, gestoras/es e coordenadoras/es, trazer em discussão a questão da crise socioambiental que o mundo vem enfrentando, assim como estratégias para a transformação de posturas, atitudes, valores e ações que envolvam a comunidade como um todo.

Nesse contexto, materiais educativos como PROBIO - Educação Ambiental (SAITO, 2006), traz metodologias e estratégias que contribuem para dinamizar e aperfeiçoar a prática docente sobre a biodiversidade, valorizando a realidade e o contexto sociocultural que o estudante está inserido (ALMEIDA; OLIVEIRA; SAITO, 2010). Bartasson (2012) identificou, por meio de mapas conceituais, grande potencial para o desenvolvimento do conteúdo relacionado à extinção de espécies com a utilização desse mesmo material didático no contexto escolar, contribuindo para a prática docente, trazendo de forma articulada as questões socioeconômicas e culturais por meio de problematizações em relação aos conflitos reais existentes em todos os biomas brasileiros (SAITO; ALMEIDA, 2006). Dessa forma, analisar as concepções sobre biodiversidade atribuídas pelos sujeitos envolvidos no processo 
educativo no ambiente escolar é fundamental para a definição de propostas educativas e ações que permitam o envolvimento crítico e transformador a respeito das questões sociais, culturais, econômicas e ambientais que giram em torno da biodiversidade.

Sendo assim, o presente trabalho teve como objetivo investigar as concepções apresentadas pelas professoras de Ciências e estudantes do $7^{0}$ ano do Ensino Fundamental II de escola municipal de São Carlos (SP) sobre o termo biodiversidade, como forma de contribuir para a elaboração de propostas educativas que visam a reflexão sobre a importância da conservação da diversidade biológica, em uma perspectiva de EA crítica, emancipatória e transformadora.

\section{Caminhos metodológicos}

\section{Público participante}

A pesquisa envolveu como público participante uma turma de 19 estudantes do $7^{\circ}$ ano do Ensino Fundamental II e três professoras de Ciências de Escola Municipal de Educação Básica (EMEB) de São Carlos, estado de São Paulo. Para que as professoras e os estudantes pudessem participar de todo o processo de pesquisa, foi necessário encaminhar uma cópia do Termo de Consentimento Livre e Esclarecido (obtido a partir da aprovação do Comitê de Ética em Pesquisa em Seres Humanos da Universidade Federal de São Carlos, processo 23112.004381/2011) e do Termo de Uso de Imagens. Vale ressaltar que para garantir 0 anonimato das professoras, foram utilizados nomes fictícios na apresentação dos resultados.

\section{Abordagem qualitativa da pesquisa}

Utilizamos a abordagem qualitativa para garantir a aproximação entre a pesquisadora e os sujeitos do estudo, privilegiando o processo do desenvolvimento da pesquisa ao invés de apenas seu produto (LUDKE \& ANDRÉ, 1986) e por ser coerente com uma perspectiva crítica de educação ambiental (CARVALHO, 2004).

Nessa perspectiva, na investigação foram realizadas entrevistas semiestruturadas com cada professora e questionários com os estudantes, contendo as seguintes questões: "O que você entende por biodiversidade?", "Cite palavras/conceitos que estão relacionados com a biodiversidade" e "Como você desenvolve essa temática em sala de aula?", sendo essa última apenas utilizada na entrevista com as professoras.

Além do processo investigativo e exploratório para o levantamento de concepções e práticas sobre a biodiversidade no ambiente escolar, a pesquisa apresentou um caráter participativo, pois a partir nas análises dos dados, iniciou-se o processo de elaboração de um material educativo sobre biodiversidade de forma colaborativa com as professoras. Sendo assim, 
utilizamos referenciais teóricos da pesquisa-ação-participante (BRANDÃO, 2005; JACOBI, 2005; TOZONI-REIS, 2005, 2007; VIEZZER, 2005; ROBOTTOM, 2006; OLIVEIRA, 2011), uma vez que essa metodologia tem como ponto de partida a realidade concreta da vida cotidiana dos sujeitos envolvidos com o processo educativo (BRANDÃO, 2005) e procura produzir conhecimentos sobre a realidade estudada a fim de construir um processo participativo com os envolvidos na pesquisa (TOZONI-REIS, 2005), em busca de uma "educação conscientizadora e libertadora" (OLIVEIRA, 2011).

\section{Resultados e discussão}

Para a análise dos dados utilizamos a Análise Textual Discursiva (ATD) a partir das recomendações de Moraes (2007), na qual os dados podem ser submetidos a textos já existentes ou produções a partir de entrevistas e observações, com o objetivo de aprofundar os fenômenos que se investiga. Nessa metodologia o autor descreve que ao examinarmos um texto qualitativamente deve ser considerado um ciclo de eventos, como o processo de unitarização que implica em examinar detalhadamente 0 material, identificando unidades de análise; categorização que remete ao processo de estabelecer relações entre as unidades de análise; construção de um metatexto que incorpore as descrições feitas das categorias estabelecidas; e, finalmente, o processo de teorização que simboliza interpretação das informações obtidas.

Para estabelecer as categorias dos dados analisados, as concepções de biodiversidade foram categorizadas a partir das três dimensões, a priori, descritas por Lévèque (1999): diversidade de espécie, diversidade genética e diversidade ecológica. Além dessas dimensões, utilizamos a categoria de diversidade inclusiva (THIEMANN, 2013) que indica a presença humana como parte constituinte da biodiversidade.

\section{Concepções de biodiversidade e práticas educativas apresentadas pelas professoras:}

A entrevista com as professoras iniciou-se com a pergunta: "O que você entende por biodiversidade?". As respostas das três professoras foram similares à definição encontrada na literatura, pois indicaram um conceito de diversidade de espécie sobre biodiversidade, que segundo Lévêque (1999), trata-se da totalidade de espécies presentes em um determinado ambiente, desde as bactérias e protistas até os reinos das plantas e animais.

Entretanto, quando perguntamos a elas exemplos de conceitos ou palavras que julgariam estar relacionadas com a biodiversidade, observamos que o conceito de diversidade ecológica (comunidade/ecossistemas) também está presente e, segundo Lévêque (1999), esta conceituação pode ser entendida como um ecossistema desde uma poça de água até uma floresta tropical, as variações existentes em cada ambiente e as interações que os 
organismos fazem entre seus níveis. A seguir (Tabela 1) temos uma síntese das respostas correspondentes às duas perguntas mencionadas acima:

Tabela 1: Coexistência de concepções atribuídas à biodiversidade em suas questões das entrevistas com as professoras.

\begin{tabular}{|c|c|}
\hline \multicolumn{2}{|c|}{ Coexistência de concepções sobre biodiversidade } \\
\hline $\begin{array}{c}\text { Pergunta 01: O que você entende sobre } \\
\text { Biodiversidade? }\end{array}$ & $\begin{array}{c}\text { Categoria de } \\
\text { Biodiversidade }\end{array}$ \\
\hline $\begin{array}{c}\text { Mariana: "Diversidade de seres vivos em geral (...)”. } \\
\text { Paula: "(...) diferentes espécies que existe e se } \\
\text { relacionam". } \\
\text { Daniela: "O que eu entendo e o que é o que eu passo (...) } \\
\text { é bem o que a palavra ta querendo dizer: bio = vida, } \\
\text { diversidade de seres. Eu falo que é isso, a diversidade de } \\
\text { seres vivos que vivem no ambiente”. }\end{array}$ & $\begin{array}{l}\text { Diversidade de } \\
\text { espécies }\end{array}$ \\
\hline $\begin{array}{l}\text { Pergunta 02: Cite palavras/conceitos sobre } \\
\text { Biodiversidade }\end{array}$ & $\begin{array}{l}\text { Categorias de } \\
\text { Biodiversidade }\end{array}$ \\
\hline $\begin{array}{l}\text { Mariana: "Equilíbrio ecológico; cadeia e teia; interferência } \\
\text { humana; relação dos animais dos seres vivos; relações } \\
\text { ecológicas (harmônicas e desarmônicas)". }\end{array}$ & $\begin{array}{l}\text { Diversidade } \\
\text { ecológica; } \\
\text { Diversidade } \\
\text { Inclusiva }\end{array}$ \\
\hline $\begin{array}{l}\text { Paula: "Ecologia, seres vivos, meio biótico, meio abiótico, } \\
\text { diversidade". }\end{array}$ & $\begin{array}{l}\text { Diversidade } \\
\text { ecológica }\end{array}$ \\
\hline $\begin{array}{l}\text { Daniela: "(...) interação, variedade, seres vivos, meio } \\
\text { ambiente e educação ambiental". }\end{array}$ & $\begin{array}{l}\text { Diversidade } \\
\text { ecológica }\end{array}$ \\
\hline
\end{tabular}

Fonte: Autoria própria.

A partir dessas duas questões observamos que para um mesmo conceito podem existir diferentes concepções e sentidos atribuídos, reforçando o que lared et al. (2010) afirmaram, quando explicitam a coexistência de tendências dentro de uma mesma prática educativa e nas falas das professoras em questão, ressaltando a impossibilidade de atribuir uma única tendência a cada unidade de análise. Além disso, esses dados coincidem com a afirmação de Wals (1999) sobre a inexistência de uma única e fixa definição para o termo biodiversidade, enfatizando que sua conceituação pode oscilar de acordo com diversas interpretações que são dadas e a dificuldade de dar sentido a um contexto específico.

Em complemento a essas informações obtidas com a primeira pergunta (O que você entende sobre biodiversidade?), um estudo intitulado "O que os brasileiros pensam sobre a biodiversidade" (BRASIL, 2006), aponta que 79\% dos entrevistados (de um total de 855 pessoas), afirmam que a destruição da biodiversidade significa diminuir a quantidade de animais e vegetais no planeta 
Terra, ou seja, grande parte da população apresenta o conceito de diversidade de espécies como sendo o mais comum e difundido em seu conhecimento.

Após o diálogo com as professoras sobre concepções de biodiversidade, perguntamos de que forma eram desenvolvidas as práticas educativas, quais estratégias as professoras utilizavam em sala de aula para abordar o assunto e como realmente era tratada essa questão. Os recursos e estratégias mais mencionados foram: o uso de filmes e imagens; atividades envolvendo os conteúdos programáticos de Ciências; na abordagem do tema biomas; e na utilização de materiais educativos do $\mathrm{CDCC}^{3}$, como podemos observar nos exemplos abaixo (Tabela 2):

Tabela 2: Exemplos de estratégias utilizadas pelas professoras para abordar a biodiversidade em sala de aula.

\begin{tabular}{l}
\hline Estratégias utilizadas para abordar a biodiversidade em sala: \\
\hline Mariana: "(...) Material do CDCC, trazendo figuras, trabalhando com filme \\
também, (...) as vezes trago um vídeo da Amazônia. \\
\hline Paula: "(..) quando você fala de outras aulas de ciências você sempre acaba \\
envolvendo biodiversidade, (...) até quando você fala de CTS/A, você também \\
acaba falando das pessoas que se relacionam, a sociedade. Então não é \\
segmentado, é tudo junto”. \\
Daniela: "(...)agora falando de biomas eu consegui colocar biodiversidade nesse \\
tema, de alguns biomas específicos, né. Eu falei até agora, por exemplo, de \\
floresta amazônica”.
\end{tabular}

Fonte: Autoria própria.

A partir do exposto, podemos observar que não existe uma única forma de abordar a temática e que muitas vezes ela pode estar inserida em outros contextos abordados em sala de aula, como nos conceitos da zoologia e da ecologia, remetendo ao conteúdo trabalhado no Ensino de Ciências, através da perspectiva Ciência, Tecnologia, Sociedade e Ambiente (CTS/A), como destacado por duas das professoras participantes. Nesse sentido, observamos que existe um potencial para o desenvolvimento de práticas educativas sobre biodiversidade em uma interface entre a educação ambiental crítica e o ensino de ciências. Para Lima e Copello (2007), é possível estabelecer esse elo entre a perspectiva CTS e a EA, uma vez que ao propor discussões democráticas e abertas aos alunos acerca das implicações dos movimentos tecnológicos e da ciência para a sociedade, estamos trazendo alguns princípios da EA como a formação de cidadãos críticos que podem se posicionar e discutir soluções que interfiram na sociedade. Além disso, partindo do pressuposto de que a

\footnotetext{
${ }^{3}$ CDCC - Centro de Divulgação Científica e Cultural - Universidade de São Paulo (USP). Apresenta um acervo com materiais didáticos que podem ser utilizados por professoras/es da rede de ensino como forma de complementar os conteúdos abordados em sala de aula.
} 
perspectiva CTS/A considera uma educação política, perspectiva reiterada por Reigota (1991), que aponta a formação para a cidadania a partir da reflexão do "por que fazer" e depois do "como fazer", identificamos outro indício da interface entre os princípios da perspectiva CTS/A e da EA para o ambiente escolar.

Além desses resultados, identificamos uma ausência em projetos ou ações pontuais sobre biodiversidade e educação ambiental nesse contexto escolar, fato que culminou na construção participante de um material didático, contendo atividades educativas e roteiros de visitas monitoradas sobre a biodiversidade de São Carlos (MARTINS, 2013), tendo como base as dimensões da prática educativa descritas por Carvalho (2006).

\section{Concepções de biodiversidade apresentadas pelos estudantes}

A primeira pergunta do questionário estava relacionada com o que os participantes entendiam por biodiversidade e a maioria, 14 estudantes (75\% das respostas), sinalizou a biodiversidade segundo o conceito de diversidade de espécies, ou seja, a totalidade de espécies presentes num determinado ambiente (LÉVÊQUE, 1999). Dentre essas respostas, apenas um aluno (5\% das respostas) não respondeu essa questão e três (15\% dos participantes) responderam em outra categoria de análise. Podemos observar essa constatação claramente nas seguintes respostas (Tabela 3):

Tabela 3: Concepções de biodiversidade apresentadas pelas/os alunas/os participantes.

\begin{tabular}{l|c}
\hline \multicolumn{3}{c}{ Exemplo de frases sobre conceito de biodiversidade } \\
\hline Pergunta 01: O que você entende por Biodiversidade? & $\begin{array}{c}\text { Categoria de } \\
\text { Biodiversidade }\end{array}$ \\
\hline "É usado para exprimir a variedade de indivíduos, de & \\
espécies, variedade de vida". & Diversidade de \\
"A vida dos seres vivos, a diversidade de seres vivos". & \\
"Diversas coisas na natureza, riqueza de espécies". \\
"Bio - vida, Diversidade - variedade, diversos tipos de vida, \\
animais".
\end{tabular}

Fonte: Autoria própria.

No gráfico abaixo (Figura 1) podemos observar os dados numéricos das respostas apresentadas nesse primeiro questionamento: 


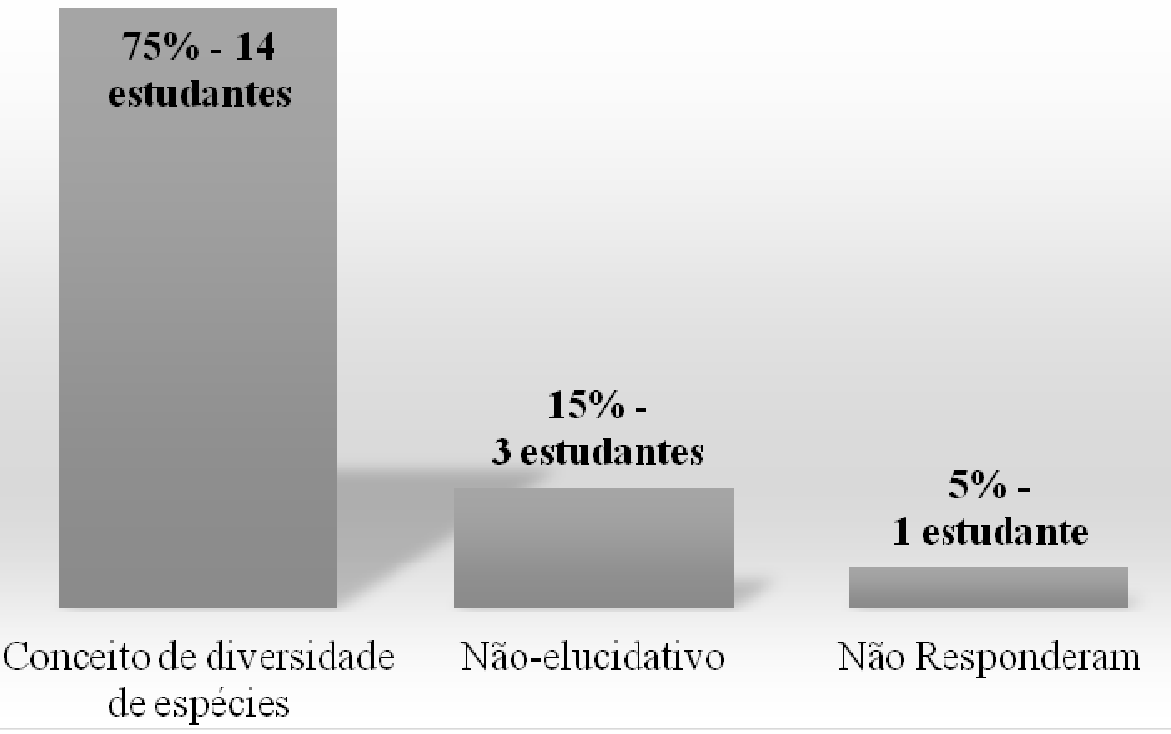

Figura 1: Porcentagens de cada tipo de resposta à pergunta "O que é biodiversidade para você?”. Fonte: Autoria própria.

Fica evidente que a concepção mais simples e mais clássica presente nas respostas dos alunos é da biodiversidade como riqueza de espécies, ou seja, a quantidade de espécies diferentes que habitam um determinado espaço. Em complemento a essa questão, pedimos para que os estudantes escrevessem cinco palavras que julgavam estar relacionadas com biodiversidade e encontramos três categorias de respostas obtidas (Tabela 4):

Tabela 4: Palavras apresentadas pelos estudantes sobre o conceito de biodiversidade.

\begin{tabular}{l|c}
\hline \multicolumn{2}{c}{ Exemplo de palavras sobre conceito de biodiversidade } \\
\hline $\begin{array}{c}\text { Pategoria de } \\
\text { Pergunta 01: Cite cinco palavras sobre } \\
\text { biodiversidade }\end{array}$ & $\begin{array}{c}\text { Diversidade de } \\
\text { espécies e ecológica. }\end{array}$ \\
\hline "Florestas, animais, arvores, ar e vida". \\
"Florestas, as matas, árvores, o ar e a vida". & $\begin{array}{c}\text { Diversidade de } \\
\text { espécies. }\end{array}$ \\
\hline "Gato, sapo, cobra, rã, coelho". & $\begin{array}{c}\text { Diversidade de } \\
\text { espécies }\end{array}$ \\
\hline "Arara, mangueira, coqueiro, macaco, abacateiro". & "Arvores, plantas, animais, água, bactérias e homem". \\
"Plantas, animal, bactéria, homem". & "Seres vivos, animais, seres humanos". \\
\hline
\end{tabular}

Fonte: Autoria própria.

Nessas respostas observamos a coexistência de duas categorias de biodiversidade na mesma frase, sendo que três respostas $(15,7 \%$ dos questionários) apresentaram o conceito de diversidade de espécie; outras três Revbea, São Paulo, V. 10, N 1: 127-145, 2015. 
(15,7\% dos questionários) explicitaram o conceito de diversidade de espécies e diversidade ecológica (comunidades/ecossistemas); seis respostas (31,6\% dos questionários) apresentaram os conceitos de diversidade de espécies e diversidade inclusiva; e sete participantes (36\%) não responderam (Figura 2):

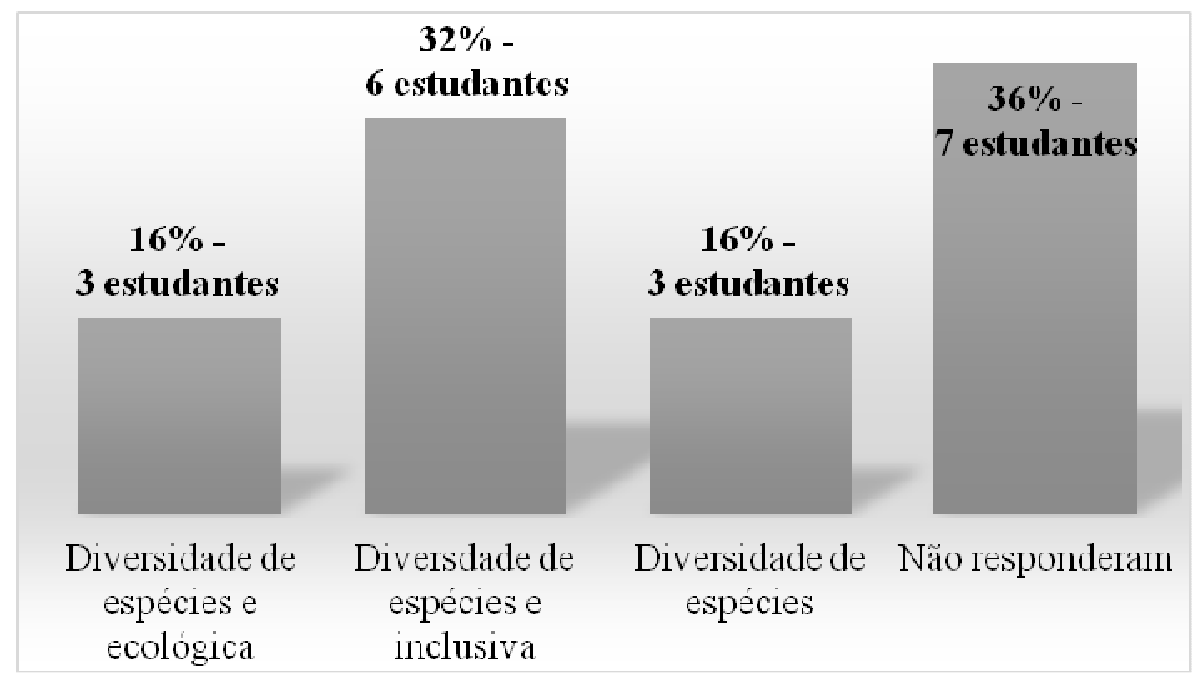

Figura 2: Porcentagens de cada tipo de resposta à pergunta "Cite cinco palavras sobre biodiversidade". Fonte: Autoria própria.

Interessante observar que nas duas perguntas a predominância das respostas foi em relação ao conceito de diversidade de espécies, entretanto, somente quando perguntamos sobre cinco palavras envolvendo a temática que a categoria de diversidade ecológica surgiu. Essa constatação está intimamente relacionada com o que Wals (2006) aponta sobre a não existência de uma definição única e fixa sobre o conceito de biodiversidade e, além disso, essas respostas se articulam com as falas das professoras, uma vez que elas também apresentaram concepções de diversidade de espécies e ecológica nas suas respostas.

No estudo "O que os brasileiros pensam sobre a biodiversidade?" (Brasil, 2006) as palavras relacionadas com biodiversidade mais citadas pelos entrevistados foram: plantas $(72 \%)$, animais $(70 \%)$, florestas $(70 \%)$, água $(62 \%)$, solo/terra $(60 \%)$ e rios $(59 \%)$. As palavras referentes às cidades tiveram apenas $17 \%$ de citação e a palavra homens e mulheres, $36 \%$. Isso vem ao encontro do que foi observado nas respostas dos estudantes, destacando que a biodiversidade ainda é associada com elementos naturais que estão distantes da presença e do cotidiano humano, evidenciando a necessidade de ampliar a compreensão sobre esse conceito no ambiente escolar, no sentido de promover um pensamento multidimensional sobre a diversidade biológica.

Outra observação que julgamos pertinente considerar foram as respostas de três alunos que articularam palavras sobre biodiversidade com exemplos do cotidiano, como "gato, sapo, cobra, arara, mangueira, macaco, 
abacateiro", evidenciando uma grande potencialidade de abordar e valorizar a diversidade biológica presente na realidade dos estudantes, pouco abordada em sala de aula. Segundo Bizzo (2001), os alunos tem fácil acesso ao entendimento de questões que estão relacionadas com o cotidiano, uma vez que essas informações obtidas são provenientes de vivências, saberes populares, culturas e mitos. Sendo assim, a escola apresenta condições para abordar temas relevantes como a conservação da biodiversidade trazendo temáticas e exemplos que valorizem os elementos do contexto social e cultural das/dos estudantes, como a questão da ocupação humana em áreas protegidas, áreas verdes urbanas, fauna e flora da região.

\section{Correlações entre as concepções apresentadas pelas professoras e pelos estudantes}

A partir do exposto anteriormente sobre as concepções de biodiversidade que estudantes e professoras de Ciências apresentaram, realizamos uma compilação das informações obtidas como forma de traçar um paralelo entre suas falas para observar a coexistência de concepções atribuídas ao termo com o intuito de destacar lacunas e potencialidades que poderiam direcionar a elaboração de um material de educação ambiental visando à conservação da biodiversidade.

$\mathrm{Na}$ análise dos dados observamos duas situações, sendo que a primeira é referente às respostas obtidas à pergunta "O que é biodiversidade para você?" e a outra referente à pergunta "Cite cinco palavras sobre biodiversidade" (Tabela 5):

Tabela 4: Correlações entre as concepções sobre biodiversidade apresentadas por professoras e estudantes

\begin{tabular}{c|c}
\hline \multicolumn{2}{c}{ 1. O que você entende por biodiversidade? } \\
\hline $\begin{array}{c}\text { Concepção das } \\
\text { professoras }\end{array}$ & Concepções das/os alunas/os \\
\hline $\begin{array}{c}\text { Todas as professoras - } \\
\text { Diversidade de Espécies }\end{array}$ & $\begin{array}{r}75 \%(15 \text { alunas/os }) \text { - Diversidade de espécies; } \\
5 \%(1 \text { aluno }) \text { - "Vida dos seres vivos" }\end{array}$ \\
\hline \multicolumn{2}{c}{ 2. Cite cinco palavras/conceitos sobre biodiversidade. } \\
\hline $\begin{array}{c}\text { Concepção das } \\
\text { professoras }\end{array}$ & Concepção das/os alunas/os \\
\hline $\begin{array}{c}\text { Diversidade ecológica e } \\
\text { inclusiva }\end{array}$ & $\begin{array}{c}\text { (6) (6 alunas/os) - Diversidade de espécies e } \\
\text { inclusiva; }\end{array}$ \\
& $16 \%$ (3 alunas) - Diversidade de espécies. \\
\hline
\end{tabular}


$\mathrm{Na}$ primeira pergunta observamos uma coexistência de concepções dos participantes em relação ao termo sendo que a diversidade de espécies ainda é a categoria mais abordada, o que corrobora os argumentos de Begon, Townsend e Harper (2005) de que a ideia de biodiversidade relacionada ao conceito de riqueza de espécies ainda é a concepção mais difundida na comunidade. Entretanto, quando perguntamos sobre palavras/conceitos atrelados ao termo biodiversidade, observamos que tanto as professoras quanto os estudantes apresentaram conceitos relacionados à diversidade biológica, como ecossistemas, interação com seres vivos, presença do ser humano, entre outros. Esses resultados podem ser reflexo das práticas e dos conteúdos dos livros didáticos que esses estudantes têm à disposição em sala de aula, nos indicando a importância de abordar os demais conceitos econômicos, políticos, sociais e culturais da biodiversidade entre docentes e discentes para ampliar a compreensão da complexidade do tema e dos desafios relacionados à conservação da biodiversidade. Oliveira e Kawasaki (2005) também observaram dado semelhante em sua pesquisa sobre concepções de biodiversidade entre professores de Biologia, pois identificaram que durante a construção da concepção por parte dos participantes a biodiversidade era definida apenas no nível biológico e tinha uma conotação de riqueza de espécies. Mas, quando eram questionados sobre o significado da biodiversidade para eles, para a sociedade ou para o ensino, eles agregavam valores econômicos, sociais e culturais. Esse fato contribui para a discussão de que as concepções de um grupo social, no caso professoras de Ciências, não são únicas, podendo existir diversas tendências durante suas práticas educativas, que merecem ser compreendidas.

\section{Desdobramentos da pesquisa: elaboração do material didático Caixa da biodiversidade}

A partir da constatação da ausência de práticas educativas sobre biodiversidade envolvendo os princípios da educação ambiental, tivemos como desdobramento da pesquisa realizada e seguindo a perspectiva dos princípios da pesquisa-ação-participante, a elaboração de um material educativo intitulado Caixa da biodiversidade, envolvendo a participação das professoras, coordenadora pedagógica e vice-diretora da escola. O objetivo geral desse material é promover o conhecimento e reflexão sobre a biodiversidade do município onde a pesquisa foi realizada (São Carlos - São Paulo), por meio de atividades práticas e visitas monitoradas, permitindo que os estudantes explorem as diversas dimensões da diversidade biológica e que visualizem a sua presença no seu cotidiano e nos ambientes e espaços educadores deste município, como na própria escola, no bairro, nos fragmentos de cerrado, nas matas galerias e no Parque Ecológico "Dr. Antonio T. Vianna" (MARTINS, 2013). O material está disponível para empréstimos e pode ser obtido em: http://www.cescar.ufscar.br/material didatico/martins oliveira 2014 guia de atividades de ea.pdf. 


\section{Considerações finais}

Os dados levantados na pesquisa e a elaboração participativa de material educativo nos permitiram identificar que existe uma correlação entre as concepções de biodiversidade apresentadas pelas professoras e estudantes, indicando haver uma coerência de significados abordados em sala de aula e que as concepções não são ideias únicas e restritas, podendo um mesmo indivíduo apresentar diversas tendências entre o sentido do termo para si mesmo e durante a realização de práticas educativas. Além disso, verificamos que a temática da biodiversidade é tratada de forma integrada nos componentes curriculares, favorecendo a interface entre a EA e o Ensino de Ciências, em uma abordagem CTS/A. Entretanto, não foi observada naquele contexto escolar a proposição de projetos específicos sobre a temática, que potencialmente poderiam envolver as esferas políticas, sociais, culturais, éticas e econômicas, em uma perspectiva de educação ambiental crítica.

As estratégias utilizadas pelas professoras para abordagem do tema estavam relacionadas com os conteúdos curriculares e não traziam como foco central a reflexão e o posicionamento crítico sobre as ameaças e necessidades de conservação da biodiversidade. Como desdobramento da pesquisa, com base nos dados coletados e atuação participante das professoras, elaboramos um conjunto de atividades e materiais didáticos envolvendo a temática como estratégia para reflexão sobre conservação da biodiversidade na região do município em questão. Tal desdobramento evidencia a potencialidade da pesquisa tanto para a construção do campo epistemológico da educação ambiental escolar, quanto para a formulação de práticas educativas em uma perspectiva crítica que permite valorizar os elementos relacionados à biodiversidade do contexto social e cultural dos estudantes no sentido de permitir reflexão, transformação e emancipação dos sujeitos envolvidos.

\section{Agradecimentos}

À equipe da Escola Municipal de Educação Básica de São Carlos, especialmente às professoras participantes, coordenadoras, diretoras e aos estudantes; à Fundação de Amparo à Pesquisa do Estado de São Paulo (FAPESP) pelo financiamento da pesquisa.

\section{Referências}

ALMEIDA, A.S.V.; OLIVEIRA, L.G.; SAITO, C,H. A contribuição do material educativo PROBIO/EA e seu potencial no ensino de ciências e biologia. Revista da SBEnBio, no 3, 2010.

BARTASSON, L.A. Avaliação do material didático PROBIO - Educação Ambiental a respeito de sua contribuição para a compreensão de conceitos ecológicos, a partir de mapas conceituais elaborados por alunos da Educação Básica: estudo de caso. 2012. 54f. Dissertação (Mestrado). Universidade de Brasília, Brasília, 2012.

Revbea, São Paulo, V. 10, Nº 1: 127-145, 2015. 
BEGON, M.; TOWNSEND, C.R.; HARPER, J.L. Ecology: from individuals to ecosystems. Blackwell Publishing, 4⿳亠丷厂 edição, 2005.

BIZERRIL, M. X.A.; FARIA, D. A escola e a conservação do Cerrado: uma análise no ensino fundamental do Distrito Federal. Revista Eletrônica do Mestrado em Educação Ambiental, vol. 10, jan-jul, 2003.

BIZZO, N. Ciências: fácil ou difícil? São Paulo: Ática, 2000

BRANDÃO, C.R. Pesquisa Participante. In: FERRARO Jr., L.A. (orgs) Encontros e Caminhos: formação de educadoras(es) ambientais e coletivos educadores. Brasília: MMA, Diretoria de Educação Ambiental, 2005, p.259-266.

BRASIL. Ministério do Meio Ambiente. Secretaria de Biodiversidade e Florestas. Convenção sobre diversidade biológica: Conferência para adoção do texto acordado da CDB - Ato Final de Nairobi. Brasília: MMA/SBF, 1992.

BRASIL. Ministério da Educação. Parâmetros Nacionais Curriculares. Temas Transversais, $1997 . \quad$ Disponível em: http://portal.mec.gov.br/seb/arquivos/pdf/meioambiente.pdf

BRASIL. Ministério da Educação. Política Nacional de Educação Ambiental, 1999.

BRASIL. Ministério do Meio Ambiente. Instituto de Estudos de Religião. $\mathbf{O}$ que os brasileiros pensam sobre biodiversidade: pesquisa nacional de opinião (comparação com dados dos estudos de 1992 - 1997 - 2001). Brasília: MMA/ISER/VOX Populi, 2006, 61p.

CARVALHO, I.C.M. Educação Ambiental Crítica: nomes e endereçamentos da educação In: LAYRARGUEES, P. P. (coord.) Identidades da Educação Ambiental Brasileira. Brasília: Ministério do Meio Ambiente, 2004.

CARVALHO, L.M. A temática ambiental e o processo educativo: dimensões e abordagens. In: CINQUETTI, H.S.; LOGAREZZI, A. Consumo e resíduo: fundamentos para o trabalho educativo. São Carlos: Edufscar, 2006. p. 19-41.

CASTRO, S.C.P. Mapeamento Ambiental como proposta para a construção dos conceitos Biodiversidade e Cerrado no Ensino de Biologia. 2009. $108 f$. Dissertação (Mestrado). Universidade Federal de Goiás, Goiás, 2009.

GONZÁLES-GAUDIANO, É. Educación Ambiental para la biodiversidade: reflexiones sobre conceptos y práticas. Tópicos em Educación Ambiental, 4 (11), pag. 76-85, 2002.

HELENE, E.M.; MARCONDES, B. Evolução e biodiversidade: o que nós temos com isso? São Paulo: Scipione, 1996.

IARED, V.G. Concepções de educação ambiental e perspectivas pedagógicas de professoras do ensino fundamental e as potencialidades do Pólo Ecológico de São Carlos (SP). 2010. 183f. Dissertação (Mestrado). Universidade Federal de São Carlos, São Carlos, 2010. 
JACOB, J. Participação. In: FERRARO Jr., L.A. (orgs) Encontros e Caminhos: formação de educadoras(es) ambientais e coletivos educadores. Brasília: MMA, Diretoria de Educação Ambiental, 2005, p. 229-236.

KAWASAKI, C.S.; OLIVEIRA, L.B. Biodiversidade e educação: as concepções de biodiversidade dos formadores de professores de biologia. Atas do IV Encontro Nacional de Pesquisa em Educação em Ciências (IV ENPEC), 2003.

LIMA, C.A.; COPELLO, M.I. Educação Ambiental desde o enfoque ciência/tecnologia/sociedade (CTS) - um possível caminho. Pesquisa em Educação Ambiental, v. 2, n. 2, p. 173-196, 2007.

LÉVÊQUE, C. A biodiversidade. Editora da Universidade do Sagrado Coração, 1999.

LOUREIRO, C.F.B.; COSSíO, M.F.B. Um olhar sobre a educação ambiental nas escolas: considerações iniciais sobre os resultados do projeto "O que fazem as escolas que dizem que fazem educação ambiental?". In: MELO, S. S.; TRABJER, R. (coord.). Vamos cuidar do Brasil: conceitos e práticas em educação ambiental escolar. Brasília, MEC, CGEA: MMA, DEA: UNESCO, pp. 58-71, 2007.

LOUREIRO, C.F.B. Educação ambiental transformadora. In: LAYRARGUES P.P. (coord.). Identidades da educação ambiental brasileira. Brasília: Ministério do Meio Ambiente, pp. 65-84, 2004.

LÜDKE, M.; ANDRÉ, M.E.D.A. Pesquisa em educação: abordagens qualitativas. São Paulo: EPU, 1986

MARTINS, C. Biodiversidade e Educação Ambiental: concepções e construção participativa de uma proposta educativa (Ensino Fundamental II - São Carlos, SP). 90f. 2013. Monografia (Graduação). Universidade Federal de São Carlos, São Carlos, 2013.

MORAES, R, Mergulhos discursivos: análise textual qualitativa entendida como processo integrado de aprender, comunicar e interferir em discursos. In: Metodologias emergentes de pesquisa em educação ambiental. GALIAZZI, M. C.; FREITAS, J. V. (org.), 2 ed., ljuí: Ed. Unijuí, 2007, p. 85 -114.

OLIVEIRA, H.T.. Pesquisa-ação-participante ou pessoas que aprendem participando: de qualquer maneira, PAP! In: (orgs) OLIVEIRA, H.T.; SANTOS, S.A.M.; DOMINGUEZ, I.G.P.; KUNIEDA, E. Cadernos do Cescar - Educação Ambiental - Caderno 1 - Os fundamentos e políticas públicas de Educação Ambiental na constituição do Coletivo Educador de São Carlos, Araraquara, Jaboticabal e Região. São Carlos: Gráfica e Editora futura, p. 47-57, 2011.

OLIVEIRA, L.B.; KAWASAKI, C.S. Concepções de biodiversidade nos professores de biologia. Atas do $\mathrm{V}$ Encontro Nacional de Pesquisa em Educação em Ciências (V ENPEC), n 5, 2005.

OLIVEIRA, A.D.; MARANDINO, M. A biodiversidade no saber sabido: investigando concepções de biodiversidade na literatura e entre pesquisadores. Revista de Educação, Ciências e Matemática, vol. 1, no 1, 2011.

Revbea, São Paulo, V. 10, Nº 1: 127-145, 2015. 
REIGOTA, M. Meio ambiente e representação social. S. Paulo: Cortez, 2004. RICKLEFS, R.E. A Economia da Natureza. Rio de Janeiro: Guanabara Koogan SA, 2003.

RIO DE JANEIRO. Tratado de Educação Ambiental para Sociedades Sustentáveis e Responsabilidade Global, de junho de 1992. Disponível em: http://portal.mec.gov.br/secad/arquivos/pdf/educacaoambiental/tratado.pdf.

ROBOTTOM, I. Participatory research in EE: some issues of epistemology and methodology. Pesquisa em Educação Ambiental, vol. 1, no1, p.11 - 25, 2006.

ROOS, A. A biodiversidade e a extinção de espécies. Revista Eletrônica em Gestão, Educação e Tecnologia Ambiental, v 7, n 7, p. 1494 - 1499, 2012.

SAITO, C.H. (Org). Educação Ambiental Probio: Livro do Professor. Brasília: MMA, Departamento de Ecologia da UnB, 2006.

SAITO, C.H.; ALMEIDA, L.E. Conservação da biodiversidade e valorização do componente educacional. Floresta e Ambiente, vol. 13, № 2, p. 66-74, 2006.

SILVA, L.C.; SILVA, R.L.F. Abordagens da biodiversidade em artigos de mídia impressa e possibilidades de contextualização na perspectiva de uma educação ambiental crítica. Atas VI Encontro "Pesquisa em Educação Ambiental", 2011.

TOZONI-REIS, M.F.C. Pesquisa ação: compartilhando saberes; pesquisa e ação educativa ambiental. In: FERRARO Jr., L. A. (orgs) Encontros e Caminhos: formação de educadoras(es) ambientais e coletivos educadores. Brasília: MMA, Diretoria de Educação Ambiental, 2005, p. 269-276.

TOZONI-REIS, M.F.C. (Org). A pesquisa-ação-participante em Educação Ambiental: reflexões teóricas. São Paulo: Anablume; Fapesp; Botucatu: Fundibio, 2007

THIEMANN, F.T.C.S. Biodiversidade como tema para educação ambiental: contextos urbanos, sentidos atribuídos e possibilidades na perspectiva de uma educação ambiental crítica. 2013. 159f. Tese (Doutorado). Universidade Federal de São Carlos, São Carlos, 2013.

VALENTI, M.W. Educação Ambiental dialógico-crítica e a conservação da biodiversidade no entorno de áreas protegidas. 2014. 139f. Tese (Doutorado). Universidade Federal de São Carlos, São Carlos, 2014.

VIEZZER, M. Pesquisa-Ação-Participante (PAP). In: FERRARO Jr., L. A. (orgs) Encontros e Caminhos: formação de educadoras(es) ambientais e coletivos educadores. Brasília: MMA, Diretoria de Educação Ambiental, 2005, p.257-294.

WALS, A.E.J. Environmental education and biodiversity. ICK-report No. 36. Wagningen: National Reference Centre for Nature Management, 120p. 1999.

WEELIE, D.V. Making biodiversity meaningful through environmental education. International Journal of Science Education, v. 24, № 11, p.1143-1146, 2002.

WILSON, E.O. Diversidade da vida. São Paulo: Companhia das Letras. 1992. 